\title{
Las regalías contractuales como mecanismo alternativo de financiamiento de la industria minera
}

\author{
Rafael Lengua Peña ${ }^{(*)}$ \\ Abogado por la Universidad de Lima. \\ Máster en Derecho (LL.M.) por la Universidad de Columbia (James Kent Scholar). \\ Miembro Asociado de ADV Editores - Revista ADVOCATUS.
}

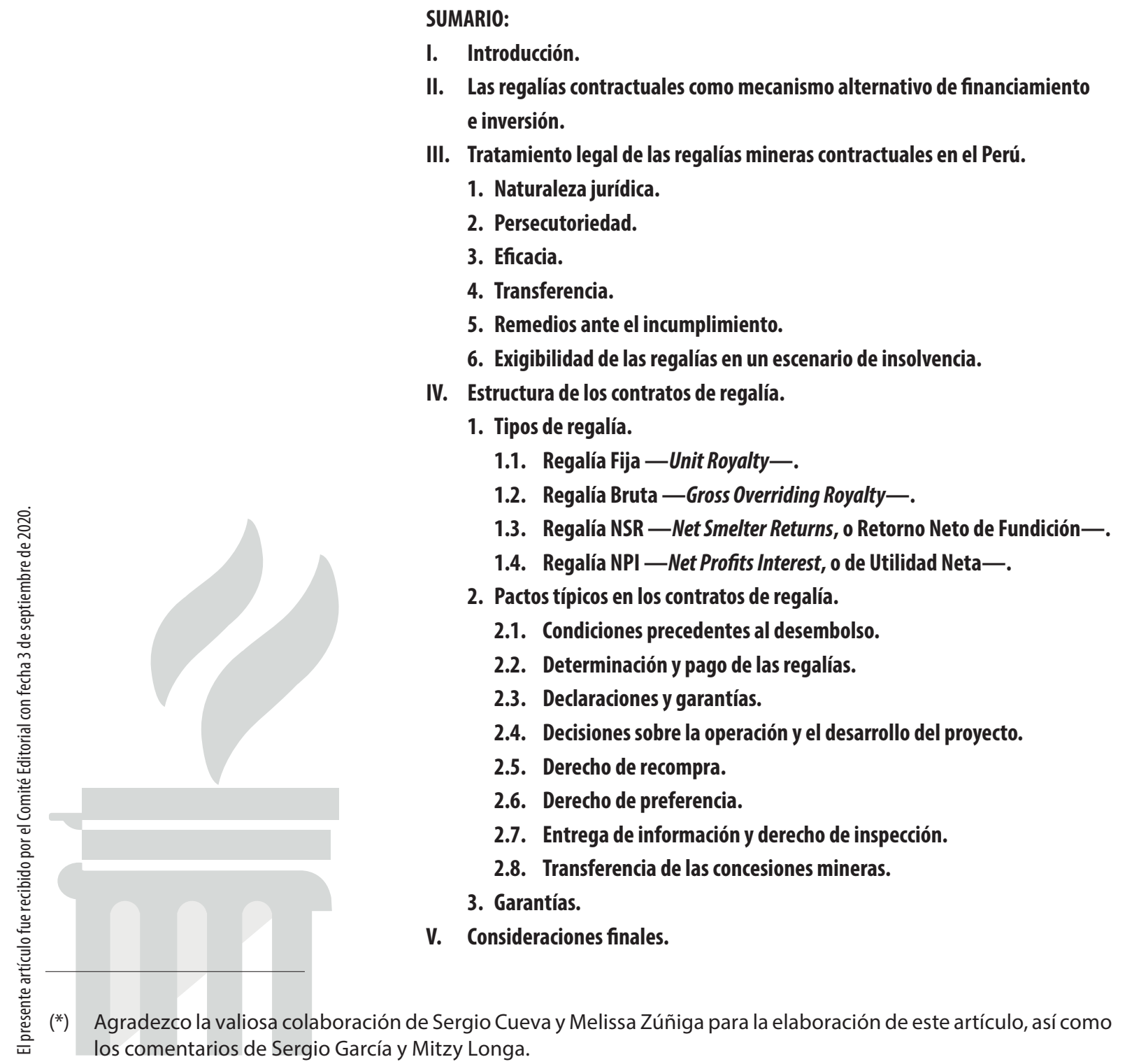




\title{
RESUMEN:
}

Con un ecosistema minero en constante evolución, las regalías contractuales emergen como un novedoso método de financiamiento para proyectos que requieren millonarias inversiones. El autor analiza el funcionamiento y aplicabilidad de este método, recién introducido en el Perú, y cómo éste encaja dentro del sistema jurídico nacional. Para ello, analiza primero la naturaleza de la regalía contractual y cómo es regulada por nuestro ordenamiento jurídico, para luego estudiar los distintos tipos que se presentan en la práctica y su contenido.

Palabras clave: minería, regalía contractual, Project Finance, proyectos mineros, Derecho Civil.

\begin{abstract}
:
With a mining ecosystem in constant evolution, contractual royalties have emerged as a new financing method for projects that require millionaire investments. The author analyzes the operation and applicability of this method, recently introduced in Peru, and how it fits into the national legal system. In order to do this, he first analyzes the nature of the contractual royalty and how it is regulated by our legal system, to then study the different types that emerge in practice and their content.

Keywords: mining, contractual royalty, Project Finance, mining projects, Civil Law.
\end{abstract}

"Royalty holders must be wary of the tendency in industries involved in specialized fields to adopt practices that become accepted through repetition - 'don't worry, we always do it this way' approach."

Karl J.C. Harries

\section{INTRODUCCIÓN}

Las regalías contractuales ${ }^{1}$ en la industria minera se han utilizado desde hace décadas como una forma de contraprestación variable a favor de los vendedores de concesiones mineras para concederles un derecho sobre una parte de los flujos que se puedan generar en el futuro por la producción y venta de minerales extraídos de la concesión minera transferida. También ha sido común observar pactos de regalías contractuales en el marco de joint ventures mineros según los cuales cuando un participante ve su participación diluida por debajo de un cierto porcentaje se le exige intercambiar sus acciones por una regalía sobre la producción minera. ${ }^{2}$

Sin embargo, desde hace no mucho tiempo, dada la limitada disponibilidad de fuentes de financiamiento tradicional de equity y deuda para la industria minera, en particular para la exploración y desarrollo de proyectos mineros, las regalías contractuales mineras se han expandido como un mecanismo alternativo de financiamiento para proyectos y operacio-

1. Es importante diferenciar las regalías contractuales mineras de la "regalía minera" legal que es definida por el artículo 2.1 de la Ley de Regalía Minera, Ley 28258, como "la contraprestación económica que los titulares de las concesiones mineras pagan al Estado por la explotación de los recursos minerales metálicos y no metálicos". Esta regalía minera está más bien asociada a la tributación minera y es objeto de regulación administrativa en su constitución, determinación, administración, distribución y utilización. Para un estudio completo sobre la aplicación de regalías mineras legales y su relación con el régimen tributario, ver: Otto, James, Craig Andrews, Fred Cawood, Michael Doggett, Pietro Guj, Frank Stermole, John Stermole, y John Tilton, Mining Royalties: A Global Study of Their Impact on Investors, Government, and Civil Society. Directions in Development, Energy and Mining (Washington, DC: World Bank, 2006). https://openknowledge.worldbank.org/handle/10986/7105.

2. Cfr.: Karl J.C. Harries, Mining Property Acquisition and Exploration Agreements (Toronto: Law Society of Upper Canada, Department of Continuing Education, 1985).

3. Los streaming consisten en el pago adelantado de una suma fija de dinero, o una serie de pagos al cumplirse ciertos hitos, que el comprador realiza al desarrollador u operador de un proyecto minero a cambio del derecho a comprar un porcentaje de su producción futura de algún mineral — generalmente un mineral secundario — a un precio 
nes mineras a través de empresas de royalties y streaming $^{3}$, así como algunos fondos de private equity ${ }^{4}$ focalizados en la industria minera. Se reconoce que los pioneros en este modelo de negocio son Seymour Schulich y Pierre Lassonde quienes adquirieron su primera regalía en 1986 para luego convertir a Franco-Nevada en la primera empresa de regalías del mundo. Hoy por hoy, además de Franco-Nevada, existen varias empresas de royalties y streaming, tales como Wheaton Precious Metals, Royal Gold, Sandstrom Gold, Osisko Gold Royalties, entre otras. Las empresas de royalties y streaming están muy activas en el mercado con amplia capacidad de fondeo para levantar recursos necesarios para financiar proyectos a través de la adquisición de regalías o streamings por montos que oscilan entre algunos millones de dólares y más de mil millones de dólares. Muchas están listadas y hoy en día tienen capitalizaciones bursátiles por miles de millones de dólares.

En el Perú, estas estructuras de regalías vienen utilizándose desde hace algún tiempo. Por ejemplo, Franco-Nevada ha revelado que, al 20 de marzo de 2020, ha adquirido regalías "Net Smelter Returns" — regalías NSR - de entre 0.1\% a $5 \%$ sobre ocho proyectos de exploración en Perú operados por diversas empresas mineras; Entrée Resources ha revelado que en julio de 2015 adquirió una regalía NSR de $0.5 \%$ sobre el proyecto de cobre Cañariaco operado por Candente Resources; y Sandstrom ha revelado que en el 2018 adquirió regalías NSR de 1\% sobre ocho proyectos de exploración en Perú operados por Pucara Resource Corp. ${ }^{5}$

Ahora bien, las estructuras contractuales utilizadas para el uso de regalías como fuente alternativa de financiamiento generalmente son importadas de otras jurisdicciones lo que hace imprescindible entender y analizar sus particularidades para adecuarlas al marco normativo peruano. Por ello, en el siguiente artículo procuramos exponer cómo y por qué las regalías se han desarrollado como un mecanismo alternativo de financiamiento para la industria minera, analizar su tratamiento bajo la normativa peruana y algunos problemas que se deben tener en consideración por la falta de regulación expresa y, finalmente, describir los tipos de regalía más comunes en el mercado, así como los pactos típicos que se utilizan en contratos de regalía. De ninguna manera pretendemos abordar todas las materias que puedan ser relevantes en el marco de la estructuración de una operación de financiamiento vía regalías, pues ello escapa el alcance del presente trabajo. Sin embargo, consideramos que este trabajo va a contribuir a tener un mejor entendimiento de la materia.

\section{LAS REGALÍAS CONTRACTUALES COMO MECANISMO ALTERNATIVO DE FINAN- CIAMIENTO E INVERSIÓN}

La industria minera es una industria intensiva en capital y, en varias de sus etapas, riesgosa. En particular, el desarrollo de proyectos mine-

determinado - usualmente igual al costo de producción estimado— por debajo del precio de mercado. Ver: Alan Monk, «Understanding Streaming and Royalty Agreements: Alternatives to Traditional Financing». Rocky Mountain Mineral Law Foundation Journal 51, n. 1.

4. Los fondos de private equity levantan capital privado de inversionistas institucionales, family offices, y high-net worth individuals y tienen un mandato de invertir esos fondos de acuerdo a sus políticas generales de inversión. En 1998 se creó Resource Capital Funds, que fue el primer fondo de private equity especializado en minería. Desde entonces, los fondos de private equity especializados en minería han crecido exponencialmente, aunque aún representan una porción pequeña del mercado. Se estima que los fondos de private equity manejan aproximadamente \$20 mil millones de los aproximadamente $\$ 2.5$ billones que gestiona la industria de private equity global. Ver: Catherine J Boggs, Private Equity's Use of Royalties as a Financing Tool. International Mining Oil \& Gas Law, Development and Investment 10a-1 (Rocky Mt. Min. L. Fdn. 2019).

5. Cfr: «Exploration», Franco-Nevada Corporation, acceso el 1 de noviembre de 2020. https://www.franco-nevada. com/our-assets/exploration/default.aspx; «Royalties», Entrée Resources, acceso el 1 de noviembre de 2020. https:// www.entreeresourcesltd.com/projects/royalties/. 
ros, especialmente aquellos que están en etapa de exploración, requiere financiadores de largo plazo que entiendan los riesgos inherentes al desarrollo de un proyecto minero, así como las oscilaciones y ciclos en el precio de los commodities. Estas características particulares de los proyectos mineros hacen que sea complicado, y en muchos casos imposible, financiarse a través de fuentes tradicionales de fondeo.

El financiamiento tradicional a través de deuda — préstamos en sus diversas modalidades o bonos - sólo está disponible para empresas mineras que tengan operaciones mineras en marcha que generen flujos de caja predecibles y que, además, cuenten con espaldas financieras que otorguen a los financiadores una certeza razonable que el financiamiento será repagado. Esto resulta entendible, pues los financiadores bajo estas estructuras de financiamiento son adversos al riesgo ya que cobran un rendimiento fijo por el financiamiento sin beneficiarse del upside de las operaciones o proyectos mineros. Por tal razón, los contratos de deuda y emisión de bonos generalmente contienen una serie de covenants, así como otras disposiciones para asegurar que la deuda sea repagada. Asimismo, se suele exigir garantías reales como colateral para asegurar el repago de la deuda en caso de incumplimiento. La magnitud de las restricciones y el paquete de garantías dependerá, en gran medida, del perfil de riesgo del deudor, siendo usual que a los deudores clasificados como investment-grade se les imponga mucho menos restricciones y obligaciones que a los deudores que califican como high yield. ${ }^{6}$

Por su parte, en la industria minera el project financing ${ }^{7}$ sólo está disponible para la construcción de proyectos mineros que cuenten con un estudio de factibilidad bancable ${ }^{8}$ y que, además, cumplan con los criterios exigidos por el mercado para el otorgamiento de este tipo de financiamientos en los cuales los financistas analizan, fundamentalmente, los flujos de caja y activos del proyecto. Los project finance para la construcción de proyectos mineros requieren pasar por procesos de due diligence económico, técnico, legal, ambiental, entre otros, bastante profundos para satisfacer los requerimientos de las instituciones financieras. En efecto, los financiadores requieren analizar y entender información sobre las propiedades mineras, reservas y recursos, factibilidad técnica del diseño de la mina seleccionado, así como del método de procesamiento elegido, costos y gastos de capital, posición en la curva de costos, comercialización de los minerales procesa-

6. Para una descripción de los términos usuales en financiamientos sindicados internacionales y emisiones de bonos high-yield, ver: Rafael Lengua, «Algunas consideraciones introductorias sobre la emisión de bonos high yield en el mercado de capitales internacional», ADVOCATUS n. 25 (2011); y Rafael Lengua, «Introducción a los contratos de crédito sindicado en el mercado financiero internacional», ADVOCATUS n. 27 (2012).

7. Por "project financing" se entiende al financiamiento para el desarrollo de un proyecto minero basado en su propia generación de flujos, sin recurso - o con recurso limitado- a los activos de los sponsors, y con la garantía de los activos del proyecto.

8. El estudio de factibilidad es un estudio técnico y económico, bastante detallado y extenso, del método de minado y procesamiento seleccionado para el desarrollo de un proyecto minero. Incluye un análisis detallado del plan de minado, método de procesamiento, aspectos metalúrgicos y operacionales, infraestructura requerida, aspectos económicos, marketing, legales, ambientales, sociales, gubernamentales; así como un análisis financiero detallado que demuestre con un alto nivel de confianza que el desarrollo del proyecto $y$, consecuentemente, la extracción de los minerales, es económicamente viable. Permite convertir los recursos en reservas. Se considera que tiene un nivel de confianza razonablemente alto - \pm entre $5 \%$ y $15 \%$ - Este tipo de estudio sirve para que el titular de un proyecto minero tome la decisión de iniciar la construcción, así como también, sirve para que las instituciones financieras financien la construcción de un proyecto. El término "bancable" se utiliza para hacer referencia a un estudio de factibilidad que satisfaga los requerimientos de las instituciones financieras. Cfr.: Victor Rudenno, The Mining Valuation Handbook: mining and energy valuation for investors and management. $3^{\circ}$ ed. (Milton: John Wiley \& Sons, 2009), 22-30. 
dos, modelo financiero, entre otros. Asimismo, se exige que los sponsors contribuyan con una porción relevante del capital para la construcción del proyecto - generalmente vía equitye imponen muchas restricciones al desarrollo y operación del proyecto por parte de los sponsors. Son pocos los proyectos mineros y sponsors capaces de satisfacer estos requerimientos.

Como resulta evidente, las estructuras de financiamiento tradicionales y el project finance resultan prohibitivas para las empresas que estén desarrollando proyectos de exploración minera. Estos proyectos no generan flujo de caja, no cuentan con un estudio que demuestre con un razonable nivel de certeza su viabilidad y, además, únicamente tienen como respaldo los activos vinculados al proyecto de exploración minera que buscan financiar.

El financiamiento de proyectos de exploración generalmente se ha realizado a través de emisiones de instrumentos de equity vía colocaciones privadas y públicas apuntando a inversionistas que estén dispuestos a asumir un riesgo alto a cambio de un alto rendimiento. Sin embargo, el principal inconveniente de este tipo de financiamiento es que diluye la participación de los sponsors y el impacto de esta dilución es bastante más pronunciado en condiciones adversas de mercado como la que se ha venido experimentando en años recientes. ${ }^{9}$

En este contexto, gracias a sus ventajas frente a las fuentes tradicionales de fondeo, las regalías y los streamings han ganado fuerza en el mercado, pues no conllevan dilución a nivel de los accionistas y tampoco imponen las restricciones típicamente atadas a la deuda. Hoy en día, existen diversas empresas de royalties y streaming como, por ejemplo, Franco-Nevada, que tiene una capitalización bursátil de más de US\$ 25,000 millones y ha invertido en cientos de regalías y streams sobre minas en diversas etapas de desarrollo - producción, exploración avanzada y exploración temprana-. Sus principales inversiones son un stream de oro y plata en la mina Cobre Panamá, un stream de plata sobre Antamina y un stream de plata y oro sobre Antapaccay. Otra empresa relevante en este mercado es Sandstrom, que tiene un portafolio de más de 200 regalías, siendo más de veinte de éstas sobre operaciones mineras en marcha.

Las regalías como mecanismo alternativo de financiamiento suponen un pago a la empresa minera a cambio del derecho a recibir por parte del titular del proyecto minero un pago en efectivo equivalente a un porcentaje de los ingresos obtenidos por la venta de los minerales producidos en las concesiones mineras a los que la regalía se vincula. Las regalías, por tanto, permiten a la empresa minera diversificar sus fuentes de fondeo y financiarse a nivel del activo, apalancándose con los prospectos del proyecto o contra recursos minerales identificados, liberando recursos para continuar buscando nuevos proyectos y diversificar su portafolio interno de proyectos. Además, a cambio de un pago fijo, conceden a los inversionistas derecho a participar en el upside futuro sin tener que asumir los costos e inversiones requeridos para ello. ${ }^{10}$

Ahora bien, así como las regalías son un mecanismo de financiamiento alternativo para las empresas mineras, también han ganado fuerza como un instrumento de inversión alterna-

9. Como señalan Mackay y Bennett, hasta el 2012, la industria minera era muy atractiva para el mercado de capitales, teniendo un buen performance incluso durante la crisis financiera del 2008-2009. Luego, con el fin del "súperciclo" de los commodities, las compañías mineras perdieron atractivo en el mercado de capitales. Las preferencias de los inversionistas cambiaron y, pese a que el financiamiento vía deuda y equity tradicional aún estaba disponible para algunas empresas mineras, la industria comenzó a buscar fuentes alternativas de financiamiento. Cfr.: Kari MacKay y Mark T Bennett, «Under the Rocks Are the Words: How a Metal Purchase Agreement Revolutionized Alternative Financing and Launched the New Majors - A Look Back at the First Decade of Metal Streaming Transactions», Rocky Mountain Mineral Law Institute 60, nº 1 (2014).

10. Aaron Careaga. «Mining Royalty Stream Financing». SSRN, 2012. http://ssrn.com/abstract=2395057. 
tivo. Los inversionistas típicamente pueden invertir en metales directamente, invertir en acciones de empresas que los produzcan o invertir en Exchange Traded Funds especializados en la industria. Las regalías - y consecuentemente, las empresas que las administranse presentan como una nueva alternativa de inversión en la industria. La inversión está limitada a un pago fijo a cambio del cual pueden obtener un flujo de efectivo relevante, si el proyecto llega a producir, y beneficiarse de cualquier expansión del proyecto y mejora en los precios de los commodities.

Al ser un mecanismo alternativo de inversión, las empresas de royalties no solo buscan financiar proyectos mineros a través de la creación de regalías, sino también adquirir regalías existentes, generalmente creadas en beneficio del vendedor de una concesión minera en el marco de su transferencia. Esto ha creado una suerte de "mercado secundario" de regalías existentes en el cual las regalías son el "activo" que circula en el mercado.

Si bien este mecanismo de financiamiento tiene claras ventajas para la industria minera, hay algunas complejidades y riesgos que vale la pena resaltar. Primero, está la valorización de la regalía. La regalía debería valorizarse asumiendo el valor presente neto de la regalía, para lo cual se debe definir la tasa de descuento, tiempo y probabilidad que se reciban los flujos proyectados. Ciertamente, estimar con precisión estas variables no es tarea sencilla y está sujeta incertidumbre. Segundo, las regalías, en tanto representan un derecho a percibir una porción del flujo generado por un proyecto minero, están sujetas a los mismos riesgos que afectan al proyecto minero, casi al mismo nivel que el equity. Así, el titular de la regalía asume los riesgos técnicos, comerciales, financieros, ambientales, legales, sociales y políticos del proyecto minero sobre el que se vincula la regalía. Tercero, al ser obligaciones de pago, las regalías están sujetas al riesgo crediticio y de cobranza inherente a cualquier obligación crediticia, así como también al riesgo de insolvencia del deudor.

\section{TRATAMIENTO LEGAL DE LAS REGALÍAS CONTRACTUALES MINERAS EN EL PERÚ}

\section{Naturaleza jurídica.}

Una primera cuestión que es muy relevante analizar con relación a las regalías contractuales mineras es cuál es su naturaleza jurídica, pues ello tiene incidencia directa en la determinación de las normas que regularán su validez, exigibilidad, circulación y oponibilidad. Esto es particularmente importante considerando que en el Perú las regalías contractuales mineras no se encuentran reguladas expresamente por norma legal alguna. ${ }^{11}$

11. Esta determinación no sólo es importante en Perú. En Canadá, un país con una larga tradición y práctica minera, por muchos años se ignoraron las reglas legales aplicables a las regalías. Fue recién en 1993, con el caso Nova Scotia Capital Corporation v. Coxheath Gold Holdings Ltd, que la industria se volvió más consciente de la naturaleza y tutela de sus regalías contractuales. En el caso Coxheath, las cortes de Nueva Escocia determinaron que las regalías de titularidad de Coxheath Gold no constituían intereses en la propiedad minera y, por ende, el trustee podía vender las propiedades mineras de la empresa insolvente libres de las regalías. Como señala K.J.C Harries: "For many years, when establishing royalties, the Canadian mining industry basically ignored the law - a failing that is not unique to the mining industry. It viewed a contractual mining royalty as having attributes that were not consistent with its legal nature." Karl J. C. Harries, «The dilemma of the mining royalty: contractual or realty interest» Natural Resources Forum 22, n 1 (1998): 1-13. Esta decisión fue luego renovada por la Corte Suprema de Canadá en el caso Bank of Montreal v. Dynex Petroleum Inc. en el cual se estableció que una regalía minera puede crear un interés en la propiedad dependiendo del lenguaje utilizado por las partes en el contrato mediante el cual se creó. En Australia, esta materia tampoco es pacífica. Según Grace y Bassett, los abogados mineros en Australia no intentan, ni recomiendan a sus clientes que traten de crear una regalía que represente un interés en la propiedad. Si bien, en opinión de estos autores, en Australia sería posible crear una regalía que tenga esta naturaleza, esto es algo que debería ser muy bien analizado y siempre existirá el riesgo que dicha naturaleza no sea reconocida judicialmente. Cfr.: Grace, John y Robert Bassett, «The AMPLA model minerals royalty agreements: securing a fair deal» Journal of Energy \& Natural Resources Law 33, n. 1 (2015): 34-58. 
En Perú, la regalía contractual minera ha sido tradicionalmente entendida por la práctica legal como una "carga" sobre la concesión minera. Bajo ese entendimiento, se ha considerado que la voluntad de las partes, mediante un pacto contractual, puede crear una "carga" de naturaleza real; la cual, una vez inscrita, persigue a la concesión minera en caso esta circule, y tiene prioridad y preferencia sobre cualquier derecho posterior que afecte a la concesión minera. ${ }^{12}$ Por tanto, por su sola inscripción la regalía será oponible y exigible a cualquier tercero que adquiera la concesión minera en el futuro y tendrá preferencia y prioridad sobre cualquier derecho posterior. ${ }^{13}$

Ahora bien, ¿es correcto afirmar que las regalías creadas en virtud de pactos contractuales tienen la naturaleza de una "carga" real? Veamos.

El término "carga" tiene tres usos en la práctica jurídica peruana. En primer lugar, es usado en sede procesal para referirse a la "carga" de la prueba, como la necesidad que tiene una de las partes procesales de probar los hechos alegados en el proceso. En segundo lugar, en sede obligacional se entiende a la "carga" como la necesidad de realizar un determinado comportamiento para satisfacer un interés propio. Por último, tiene una tercera acepción en materia de derechos reales, pero, lamentablemente, no lo suficientemente clara. Por ello, resulta crucial entender bien la definición de "carga" en materia de derechos reales para determinar si las regalías creadas en virtud de pactos contractuales comunmente celebrados en la industria minera tienen esta naturaleza.

Las normas peruanas no regulan ni definen el concepto de "carga" en materia de derechos reales, y en las distintas normas en las que se hace referencia las mismas, se les suele agrupar con los "gravámenes". Esto, en la práctica, ha significado que muchos abogados equiparen a las "cargas" con los "gravámenes" y consideren que deben tener exactamente el mismo tratamiento. ${ }^{14}$ No es motivo de este artículo entrar a ese debate por lo que simplemente definiremos a las cargas en materia de derechos reales como una relación jurídica de naturaleza real que vincula un bien a una persona creando un derecho a favor del titular de la carga y una si-

12. En esa línea, es frecuente ver contratos mineros que contengan pactos sobre la naturaleza de las regalías creadas en los siguientes términos: "la regalía perseguirá a la concesión en caso esta sea transferida"; "[los otorgantes] constituyen una carga bajo la forma de regalía (...)"; o "la transferencia de la propiedad minera acarrea por parte de los titulares la transferencia de la carga al tercero adquiriente". Por ejemplo, en el Contrato de Transferencia y Otorgamiento de Concesiones Mineras celebrado por Activos Mineros S.A.C. y Xstrata Tintaya S.A., celebrado como resultado del proceso de privatización de Las Bambas, se pactó lo siguiente: "Carga - Las REGALÍAS se constituyen como carga de las concesiones. En tal sentido, corresponde al titular de las CONCESIONES el pago de las REGALÍAS establecidas en el Contrato de Transferencia. Dicha carga se anotará en las Fichas Registrales de las CONCESIONES." Incluso, no es inusual observar partidas registrales donde los registradores hayan inscritos pactos de regalías en el rubro "cargas y gravámenes".

13. Cfr.: Patricia Núñez, Structuring Mining Agreements in Latin America», Mineral Law Series, n. 3 (2019), quien señala al respecto lo siguiente: "(...) in Perú a royalty is considered a lien on the mining property provided that in the corresponding agreement the royalty is expressly and sufficiently considered a lien and the agreement is duly registered in the corresponding public registries."

14. Al respecto, Avendaño Arana considera que la diferencia entre "gravámenes y "cargas": "(...) consiste en que los gravámenes dependen de una obligación principal, la que de incumplirse puede conllevar la venta del bien afectado. Es el caso de la hipoteca y del embargo. En las cargas, en cambio, no hay obligación garantizada. Las cargas no tienen por objeto la venta de un bien." Francisco Avendaño Arana, "Artículo 1035», en: Código Civil Comentado, Tomo V (Lima: Gaceta Jurídica, 2003), 723. En el mismo sentido, Marianella Ledesma señala: "La diferencia entre ellas radica en que los gravámenes dependen de una obligación accesoria, la que de incumplirse pueda conllevar a la venta del bien afectado, como sería el caso de la hipoteca; en cambio, con las cargas, no hay obligación garantizada. Las cargas no tienen por objeto la venta del bien, como sería el caso de las servidumbres, que se constituyen como limitación a la propiedad predial." 
tuación de desventaja para el titular del bien. ${ }^{15}$ Su naturaleza real, por tanto, las somete a las reglas aplicables a la generalidad de derechos reales y les concede todos sus atributos.

Bajo este orden de ideas, consideramos que las regalías creadas en virtud de un contrato, por más que el pacto expresamente les otorgue tal naturaleza, que su contenido se vincule a una concesión minera y que el pacto sea inscrito en registros públicos, no pueden tener la naturaleza de "carga" real, pues no existe norma alguna que las regule y les otorgue tal categoría. En el ordenamiento jurídico peruano, según se establece expresamente en el artículo 881 del Código Civil, los derechos reales se rigen bajo el sistema de numerus clausus lo que significa, como bien señala Diez-Picazo, que "no es posible que los particulares constituyan más derechos reales que aquellos que la ley establece o tipifica de una manera determinada. ${ }^{\prime \prime 6}$ Es decir, en el Perú, los derechos reales se limitan única y exclusivamente a aquellos que la ley expresamente regula. Por lo tanto, mediante pactos contractuales no pueden crearse nuevos derechos reales ni modificarse la naturaleza de los existentes. ${ }^{17}$ Eso, claro está, de ninguna manera significa que el acuerdo de regalías sea inválido o ineficaz, ni que la obligación creada por las partes no pue- da ser exigida al deudor. Simplemente, implica que ese pacto no creará un derecho real.

Siendo que no es posible crear nuevos derechos reales por autonomía privada, ¿cómo entonces podría crearse una regalía como "carga" real en virtud de un contrato? Simplemente, no es jurídicamente posible.

En Perú, la naturaleza jurídica de las regalías contractuales mineras no es real sino más bien obligacional. Las regalías vinculan un derecho de crédito, consistente en la facultad del titular de la regalía - acreedor- de exigir al titular de la concesión minera - deudor- el cumplimiento de la prestación debida, con un deber jurídico, consistente en la necesidad del deudor de pagar al acreedor la prestación debida. Para estos efectos, la "prestación debida" será el pago de una suma de dinero determinable en función a la aplicación de las reglas para la determinación de las regalías pactadas en el contrato. ${ }^{18}$

\section{Persecutoriedad.}

La persecutoriedad es un elemento de los derechos reales. Como señala Martín Mejorada, la persecutoriedad es "la condición jurídica que asegura la permanencia del beneficio (goce o ga-

15. Las cargas de naturaleza real gozan de los atributos de oponibilidad erga omnes y persecutoriedad una vez inscritas. Luis Diez-Picazo, Fundamentos del Derecho Civil Patrimonial, Tomo III (Madrid: Editorial Thomson, 2008) 82; Germán de Castro, «La obligación real», (tesis doctoral en Derecho, Universidad de Valladolid, 1998); Michele Giorgianni, «Los derechos reales», Revista Crítica de Derecho Inmobiliario 458 (1967), 24-25; y Ramón Pizarro, «Las obligaciones propter rem en el Código Civil y Comercial» Revista La Ley (2017). Para entender la naturaleza de las relaciones jurídicas, Cfr.: Freddy Escobar, «Contribución al estudio de la relación jurídica intersubjetiva», Themis 38 (1998).

16. Luis Diez-Picazo, Ensayos Jurídicos. Tres volúmenes, (Madrid: Civitas, 2011) 3361- 3383. En el mismo sentido, Martín Mejorada señala que "el sistema de numerus clausus exige que los derechos oponibles estén previstos en la ley; es decir, que la estructura y fines de estos derechos no deriven de la voluntad sino de una norma con rango de ley". Martín Mejorada, «Derechos sobre bienes y el numerus clausus», Themis 66 (2014) 177-182.

17. Las normas peruanas no contemplan la posibilidad de que puedan tener naturaleza real ni naturaleza híbrida o binaria, como las llamadas obligaciones "propter rem", entre otras figuras que son reconocidas en otras jurisdicciones. Alberto Bueres, «Obligaciones "propter rem" y sus relaciones con otras figuras», Lecturas y Ensayos 90 (2012).

18. En otros países de la región, como es el caso de Chile, Brasil y Colombia, en los que las regalías tampoco se encuentran reguladas expresamente, las regalías son también consideradas como obligaciones contractuales. Cfr.: Juan Paulo Bambach, Sandra Manrique, María Paz Pulgar, Hernán Torres y Adriano Trinidade. «Enforceability of Royalties under Latin American Legislations», International Mining Oil \& Gas Law, Development, and Investment 111. Rocky Mt. Min. L. Fdn. (2017). 
rantía), mediante la continuidad del derecho frente a ulteriores adquirentes".19

Ahora bien, si como hemos afirmado anteriormente las regalías contractuales mineras en el Perú tienen naturaleza obligacional, cabe analizar si el deber jurídico inherente a esta relación obligacional "persigue" o no a la concesión minera. Es decir, si en caso la concesión minera circule y sea transferida a un tercero, el nuevo titular, por el sólo mérito de la transferencia, asume el deber de pagar la regalía a su titular.

Es claro que en nuestro ordenamiento jurídico existen pactos contractuales que otorgan persecutoriedad a su titular como consecuencia de su inscripción registral. Ahora, en todos los casos en que ello ocurre, existe una norma expresa que les otorga tal atributo. Por ejemplo, el artículo 1591 del Código Civil señala que el pacto de retroventa es oponible a terceros cuando aparece inscrito en el correspondiente registro. Por su parte, el inciso 1 del artículo 1708 del Código Civil señala que si el arrendamiento estuviese inscrito, el adquirente del inmueble deberá respetar el contrato de arrendamiento, quedando sustituido desde el momento de su adquisición en todos los derechos y obligaciones del arrendador. Finalmente, el artículo 2023 del Código Civil establece que la inscripción de los contratos de opción otorga durante su vigencia derecho preferente sobre todo derecho real o personal que se inscriba con posterioridad.

La cuestión entonces es determinar si para el caso de las regalías contractuales mineras existe una norma similar. Es decir, si existe en nuestro ordenamiento jurídico una norma específica que establezca, como excepción a los artículos 1361 y 1363 del Código Civil, que el adquirente de una concesión minera sobre la que se haya pactado una regalía inscrita en registros públicos, deberá respetar un contrato respecto del cual no es parte, sustituyendo al deudor en ese contrato en todas las obligaciones vinculadas a la regalía.

Prácticamente no existen trabajos académicos, menos aún desarrollo jurisprudencial, en los que que se haya analizado esta materia. Sin embargo, no es infrecuente escuchar entre los abogados mineros que esta persecutoriedad sería atribuida a las regalías contractuales mineras, por su condición de contratos mineros, en aplicación del artículo 163 de la Ley General de Minería que establece textualmente que "los contratos mineros constarán en escritura pública y deberán inscribirse en el Registro Público de Minería [hoy Registro de Derechos Mineros de la Superintendencia Nacional de los Registros Públicos-SUNARP] para que surtan efecto frente al Estado y terceros."

Según esta corriente de opinión, al celebrar un pacto de regalías por escritura pública, darle la naturaleza de "carga" en el propio contrato e inscribirlo en la partida de la concesión minera, en aplicación del artículo 163 de la Ley General de Minería, dicho pacto surtiría efecto frente a terceros. Los "terceros" a los que hace referencia el artículo 163 de la Ley General de Minería serían los futuros adquirentes o cesionarios de la concesión minera y el efecto que la inscripción surtiría frente a éstos sería el deber de respetar el pacto de regalías, sustituyendo al deudor original en todas las obligaciones vinculadas al mismo. ${ }^{20}$

19. Martín Mejorada, «La persecutoriedad hipotecaria en el supremo tapete», Actualidad Jurídica 139 (2005).

20. En algunos contratos de regalías, aunque esta no suele ser la postura mayoritaria, las partes han estipulado que la regalía constituye una restricción convencional a la propiedad al amparo del artículo 926 del Código Civil según el cual: "Las restricciones a la propiedad establecidas por pacto, para que surtan efecto respecto a terceros, deben inscribirse en el registro respectivo." Queda claro que la obligación de pagar regalías en nada afecta el ejercicio de los atributos de la "propiedad" que su titular tiene sobre la concesión minera. En efecto, incluso ante la existencia de una regalía contractual, el titular de la concesión minera es libre de usar, disfrutar, disponer y reivindicar la concesión minera. 
Esta interpretación es, por decir lo menos, cuestionable. En efecto, no es claro que la eficacia frente a terceros a la que hace referencia el artículo 163 de la Ley General de Minería sea tan amplia como para considerar que, por mandato legal, el nuevo titular de la concesión minera automáticamente se sustituye en la posición deudora de la obligación de pagar la regalía previamente asumida por el transferente de la concesión minera. Creemos, más bien, que cuando el artículo 163 de la Ley General de Minería hace referencia a la eficacia frente a terceros de los contratos mineros que otorga la inscripción registral se refiere a la función de publicidad de los actos inscritos para efectos que se conozca su existencia y contenido conforme se encuentra contemplado tanto en el artículo 2012 del Código Civil como en el artículo I del Reglamento General de los Registros públicos —Resolución Nº79-2005-SUNARP/ $\mathrm{SN}-.^{21}$

El conocimiento de la existencia y contenido del pacto de regalías en virtud del principio de publicdad registral únicamente genera que ningún tercero pueda desconocer su existencia. Sin embargo, ese conocimiento no puede suponer que el adquirente de la concesión minera asuma automáticamente los deberes jurídicos del transferente creados por el pacto de regalías. ${ }^{22}$ Es decir, por el sólo hecho de adquirir una concesión minera en cuya partida registral se haya inscrito un pacto de regalías, el adquirente no se sustituye automáticamente en la posición deudora del transferente y obligado primario al pago de la regalía contractual minera.

El efecto jurídico del conocimiento de la existencia de un pacto de regalías puede ser, por ejemplo, que el adquirente de una concesión minera no pueda desconocer la existencia de una cláusula de resolución expresa a favor del vendedor por incumplimiento en el pago de la regalía y alegar buena fe para preservar su derecho si es que el contrato de transferencia primigenio luego se resuelve por incumplimiento.

Pongamos un ejemplo. El titular de una concesión minera - "transfiriente" o "Juan" - celebra un contrato de transferencia - el "Contrato de Transferencia Primigenio" - con un adquiriente - "Junior"- en el que se incluye un pacto de regalías mediante el cual Junior pagará a favor de Juan una regalía NSR del 3\% sobre las ventas de minerales extraidos de la concesión minera - cuando esto, claro está, ocurra-. El Contrato de Transferencia Primigenio contiene una cláusula resolutoria expresa que faculta a Juan a resolver el Contrato de Transferencia Primegenio en caso de incumplimiento en el pago de la regalía. Como corresponde, el Contrato de Transferencia Primegenio es debidamente celebrado por escritura pública e inscrito en registros. Supongamos que varios años después, Junior transfiere nuevamente la concesión minera a favor de un tercer adquiriente - "Mayor" - en virtud de un nuevo contrato de transferencia - el "Contrato de Transferencia Secundario"Luego de varios años y millones de dólares de

21. Como señala Gunther Gonzales: "La publicidad registral se puede definir como el sistema de divulgación encaminado a hacer cognoscible determinadas situaciones jurídicas para la tutela de los derechos y seguridad del tráfico". Gunther Gonzales, «Bases Fundamentales del Derecho Registral» Anuario Iberoamericano De Derecho Notarial 4-5 (2015-2016).

22. Según el artículo 6, inciso d), del Reglamento de Inscripciones del Registro de Derechos Mineros — Resolución $N^{\circ}$ 052-2004-SUNARP-SN — son inscribibles en el Registro de Derechos Mineros los "actos que declaren, transmitan, modifiquen, limiten o extingan obligaciones, derechos y atributos establecidos en la Ley General de Minería (...) y disposiciones complementarias que correspondan a las concesiones". Al amparo de esta norma y el artículo 42 del mismo Reglamento, se permite la inscripción registral de cualquier contrato que verse sobre concesiones mineras, incluyendo contratos en los que se haya pactado una regalía en función a la producción de minerales extraídos de una concesión minera. 
inversión, Mayor comienza a procesar y vender minerales extraidos de la concesión minera adquirida mediante el Contrato de Transferencia Secundario. Inmediatamente, Juan exige a Mayor que le pague la regalía que Junior se obligó a pagarle bajo el Contrato de Transferencia Primigenio, argumentando que la regalía estaba inscrita en la partida de la concesión minera.

¿Estaría Mayor obligado a pagar la regalía a Juan? Creemos que no. La regalía acordada entre Juan y Junior en el Contrato de Transferencia Primigenio es una obligación que faculta a Juan a exigir a Junior - deudor- el cumplimiento del pago de la regalía conforme a los términos del Contrato de Transferencia Primigenio, y a su vez, impone a Junior el deber de pagar dicha regalía. La posición deudora en esa relación obligacional no ha sido transferida a Mayor bajo el Contrato de Transferencia Secundario como consencuencia de la inscripción de la regalía en registros públicos, puesto que no existe norma expresa alguna que imponga dicha consecuencia jurídica. ${ }^{23}$

Ahora bien, ¿eso significa que el ordenamiento jurídico no tutelará el interés de Juan en este escenario? Obviamente, no. Ante el incumplimiento de Junior, Juan podría ejercer los remedios contractuales a su disposición, incluyendo resolver el Contrato de Transferencia Primigenio, lo que ocasionaría que la titularidad de la concesión minera revierta a Juan. En este escenario, Mayor evidentemente vería complicado alegar buena fe para buscar que su derecho sea preservado, pues en mérito a la inscripción del Contrato de Transferencia Primigenio $-y$, consecuentemente, del pacto de regalías- conocía la existencia de la regalía y que Juan podía resolver el Contrato de Transferencia Primigenio en caso de incumplimiento.

Sin lugar a dudas, este es un ejemplo de "laboratorio", puesto que es casi un hecho que en la realidad, Mayor tomaría conocimiento de la existencia de esta regalía en el marco del due diligence realizado e identificaría el riesgo que Contrato de Transferencia Primigenio sea resuelto ante el incumplimiento en el pago de la regalía y, por ende, el riesgo que pueda perder en el futuro su titularidad sobre la concesión minera si no se cumple con pagar la regalía a Juan. Ante esta situación, es muy probable que Mayor decida asumir el pago de esta regalía, involucrar a Juan en el acuerdo con Junior, y descontar el valor de la regalía del precio a ser pagado a Junior. Sin embargo, el hecho que, en la práctica, esta situación vaya a ser manejada diligentemente por las partes no supone, de manera alguna, que ello se dé porque la regalía tenga el atributo de persecutoriedad.

La ausencia de persecutoriedad por mandato legal presenta un reto importante al momento de estructurar pactos de regalías en Perú, particulamente cuando son creados como mecanismo de financiamiento de proyectos mineros, pues hace necesario encontrar figuras que le otorguen a ese pacto un nivel de protección similar al que tendrían si tuvieran el atributo de persecutoriedad característico de los derechos reales.

\section{Eficacia.}

Como hemos señalado, las regalías contractuales mineras tienen naturaleza obligacional en la medida en que vinculan un derecho de crédito - consistente en la facultad del titular de la regalía de exigir al deudor el pago de una suma de dinero determinable - con un deber jurídico - consistente en la necesidad del deudor de pagar al acreedor dicha prestación-.

Ahora bien, sea que las regalías se hayan pactado como parte variable del precio por la venta de una concesión minera, como un derecho a ser intercambiado por acciones o como contraprestación a cambio de un pago en efectivo, las

23. Salvo, claro está, que en el Contrato de Transferencia Primario se haya pactado que, en caso de transferencia de la concesión minera, se deba incluir en el nuevo contrato de transferencia un pacto en favor de tercero -el vendedor original- para que se le reconozca su derecho a la regalía. 
regalías se suelen pactar antes que exista una operación minera en marcha. En esos casos, típicamente su eficacia y exigiblidad se condiciona a tres hechos fundamentales: que se haya completado el desarrollo del proyecto minero; que la operación minera comience su producción comercial; y que efectivamente se generen ingresos por la venta de minerales extraidos de la concesión minera. ${ }^{24}$ Dentro de la autonomía privada, nada impide, claro está, que las regalías sean creadas con relación a una operación minera existente, en cuyo caso, las regalías serán válidas y exigibles inmediatamente luego de celebrado el pacto conforme a sus términos.

\section{Transferencia.}

Como hemos indicado, por su naturaleza obligacional, las regalías son para su titular un derecho de crédito. Como tal, la transferencia de las regalías se regulará por las reglas generales aplicables a la cesión de derechos contempladas en los artículos 1206 y siguientes del Código Civil. En esa línea, la transferencia podrá realizarse sin el consentimiento del deudor, salvo que en el contrato se estipule lo contrario. Asimismo, la cesión deberá constar por escrito y será eficaz contra el deudor cedido desde que éste la acepta o le es comunicada fehacientemente.

Ahora, si bien conforme al artículo 1211 del Código Civil la cesión comprende la trasmisión al cesionario de los privilegios, las garantías reales y personales, así como los accesorios del derecho trasmitido ${ }^{25}$ salvo pacto en contrario; no todos los derechos vinculados a la regalía que pueden ser relevantes para el beneficiario serán transmitidos como consecuencia de la cesión del derecho, como lo serían en el caso de una cesión de posición contractual. Por ejemplo, generalmente los contratos más sofisticados donde se regula la adquisición de una regalía como mecanismo alternativo de financiamiento contienen una serie de derechos adicionales al pago mismo de la regalía como, por ejemplo, derecho a recibir cierta información financiera, derechos de visita, entre otros. Consideramos que estos otros derechos bajo un contrato de regalía no serían automáticamente transferidos junto con el derecho de regalía en virtud de una cesión de derechos efectuada al amparo del artículo 1206 y siguientes del Código Civil. En ese sentido, el mecanismo ideal para la transferencia de una regalía sería la cesión de posición contractual del contrato de regalía, lo cual exigirá la participación de las partes en el contrato original, salvo que éstas hayan prestado por anticipado su consentimiento a la cesión de posición contractual.

\section{Remedios ante el incumplimiento.}

Por su naturaleza obligacional, los remedios aplicables en caso de incumplimiento en el pago de las regalías, luego que sean exigibles según pacto correspondiente, serán aquellos pactados por las partes al amparo de su autonomía privada y, supletoriamente, los que establece el Código Civil.

Así, por ejemplo, el propio contrato puede regular el interés moratorio aplicable en caso de incumplimiento en el pago y la constitución automática en mora. Caso contrario, supletoriamente, aplicarían las reglas de constitución

24. Esto es relevante, puesto que supone que las normas del Código Civil aplicables a la "condición" como modalidad del acto jurídico sean aplicables a los pactos de regalías.

25. Según Osterling y Castillo Freire el "primer párrafo del artículo 1211 del Código Civil Peruano, determina los elementos comprendidos dentro de la cesión de derechos, salvo que se pacte en contrario. Estos son los siguientes: (a) Los privilegios, entendiéndose como tales las órdenes de prelación para el cobro de una deuda o para la ejecución de alguna garantía; (b) Las garantías reales (prenda, anticresis o hipoteca); (c) las garantías personales (fianzas); $y$ (y) los derechos accesorios del derecho cedido, vale decir, todos aquellos que se hubiesen constituido al amparo de aquel derecho." Osterling, Felipe y Mario Castillo, La cesión de derechos, 14. http://www.osterlingfirm.com/Documentos/ articulos/140_\%20La_cesion_de_derechos.pdf. 
en mora e intereses legales contempladas en el Código Civil. De la misma manera, las partes podrían pactar que el incumplimiento del pago de la regalía será una causal de resolución expresa del contrato o, en todo caso, a falta de pacto expreso, procurar resolver el contrato de acuerdo a las reglas generales sobre resolución contractual previstas en el Código Civil.

\section{Exigibilidad de las regalías en un escena- rio de insolvencia.}

Actualmente la legislación peruana utiliza dos conceptos para definir la insolvencia. Primero, una empresa será insolvente cuando no pueda cumplir con sus obligaciones por un determinado plazo. Segundo, se considerará que una empresa es insolvente cuando ha sufrido pérdidas acumuladas mayores al tercio de su capital social.

Ahora bien, ¿qué tratamiento debería otorgarsele a las regalías contractuales mineras en un escenario de insolvencia considerando que tienen naturaleza obligacional? Esta no es una cuestión sencilla de resolver, pues como indicamos las regalías no tienen una regulación específica y, por tanto, se les debe aplicar las reglas generales del Derecho Civil.

Creemos que la respuesta depende si la regalía es eficaz y exigible o no al momento de iniciarse el concurso y si, además, en ese momento existe una deuda a cargo de la empresa insolvente. En efecto, si la regalía es eficaz y exigible al momento de iniciarse el concurso y existe una deuda a cargo de la empresa insolvente, los montos adeudados al titular de la regalía serán considerados como pasivos del deudor y estarán sujetos a las reglas generales aplicables a los créditos concursales. Si, por el contrario, la regalía aún no es eficaz y exigble, para fines concursales dicha regalía no tendrá relevancia jurídica alguna. Por último, consideramos que las deudas por regalías generadas durante el concurso por la continuidad de las operaciones de la empresa minera deberán tener el tratamiento de créditos post concursales, puesto que su devengo se producirá con posterioridad al inicio del concurso.

\section{ESTRUCTURA DE LOS CONTRATOS DE RE- GALÍA}

Las regalías contractuales en la industria minera generalmente se pactan como una forma de contraprestación variable a favor de los vendedores de concesiones mineras para concederles un derecho sobre una parte de los flujos que se puedan generar en el futuro por la producción y venta de minerales extraídos de la concesión minera transferida. También se incluyen en el marco de joint ventures mineros según los cuales, cuando un participante ve su participación diluida por debajo de un cierto porcentaje, sus acciones se deben intercambiar por una regalía. Finalmente, como se ha señalado anteriormente, se utilizan como un mecanismo alternativo en la industria minera.

A continuación describiremos los tipos de regalía más comunes en el mercado, así como los pactos típicos que se utilizan en contratos de regalía que sirven como mecanismo alternativo de financiamiento de proyectos $u$ operaciones mineras. A diferencia de los pactos de regalías en el marco de venta de concesiones mineras o contratos de joint venture, en el caso de los financiamientos a través de regalías en los que las regalías son el foco principal de la relación contractual, los contratos están diseñados para regular específicamente la creación, determinación, pago, transferencia de las regalías e incluyen pactos más detallados para proteger los intereses del titular de la regalía.

\section{Tipos de regalía.}

Hay varios tipos de regalías que se usan en la industria minera. Sin embargo, se puede afirmar que los tipos más comunes de regalías en el mercado son:

\subsection{Regalía fija -Unit Royalty一.}

La regalía fija está basada en una suma dineraria fija — por ejemplo, $\$ 0.50$ - por cada unidad de medida vendida - por ejemplo, una tonelada-, sin que se le aplique deducción alguna. Este tipo de regalía generalmente se usa para minerales de poco valor que pueden 
ser vendidos sin mucho procesamiento, como por ejemplo carbón, hierro, fosfato, potasio, entre otros. Su ventaja por el lado del beneficiario es que es muy fácil de calcular y asigna al operador el riesgo de variaciones en el precio de los commodities y costos operacionales. En efecto, si los costos operacionales suben o los precios caen, esto afectará negativamente el margen operativo del operador. Por el contrato, si los costos operacionales bajan y/o los precios suben, el beneficio será íntegramente del operador. ${ }^{26}$

\subsection{Regalía bruta - Gross Overriding Royalty—.}

Este tipo de regalía se calcula como un porcentaje del precio de los minerales vendidos sin deducciones por costos de procesamiento o transporte. Este tipo de regalía también se utiliza en el caso de minerales que pueden ser vendidos sin mucho procesamiento.

\subsection{Regalía NSR — Net Smelter Returns, o Re- torno Neto de Fundición-.}

Este tipo de regalía está basada en los ingresos que recibiría un operador minero por la venta de minerales a un offtaker - generalmente asociado a una fundición o refinería-. Por esta razón, a los ingresos recibidos por la venta del mineral se le realizan una serie de deducciones por costos asumidos por el operador minero luego que el mineral sale de la mina y antes que sea vendido, tales como costos de transporte y seguros desde la mina hasta la refinería o fundición, costos de refinación y fundición, muestreo, pruebas, o marketing; así como penalidades por impurezas cobradas por la refinería o fundición. Para el caso de productores de oro, las deducciones suelen ser bajas, mientras que para el caso de metales base las deducciones son más relevantes. En este tipo de regalía no se deducen los costos operacionales, gastos de capital y otros costos y gastos del productor. Generalmente se pactan porcentajes que oscilan entre $0.5 \%$ y $3 \% .{ }^{27}$

\subsection{Regalía NPI —Net Profits Interest, o de Uti- lidad Neta-.}

Estas regalías están basadas en un porcentaje de las utilidades operativas del productor minero. Para ello, se suele crear una cuenta en la que se incluyan los gastos pre-operativos, pérdidas operativas, gastos de capital y cargos por intereses. Se calcularán las utilidades netas y se las restará de la cuenta creada. Las regalías únicamente serán pagaderas cuando efectivamente exista utilidad, es decir, desde que se cubran los costos mencionados. ${ }^{28}$ Por ello, estas regalías únicamente serán pagadas luego que el productor minero haya recuperado su inversión en el desarrollo del proyecto, incluyendo costos pre-operativos. Los porcentajes típicamente oscilan entre $7 \%$ y $15 \%$, aunque pueden ser más altos. ${ }^{29}$

Si bien cada tipo de regalía tiene sus ventajas y desventajas dependiendo de si se analizan desde la perspectiva del beneficiario o deudor, las regalías NSR son las que más se han utilizado en la industria minera y aquellas que generalmente se pactan cuando las regalías se crean en el marco de una operación alternativa de financiamiento. Este tipo de regalías es preferido por los beneficiarios porque los pagos se devengan luego de que se produzca la primera venta, no siendo necesario esperar a que el operador minero recupere su inversión. Asimismo, son más fáciles de administrar para

\section{Alan Monk, Op. Cit. 25-26.}

27. «Mining royalties in focus», NORTON, ROSE, FULBRIGHT, acceso el 1 de noviembre de 2020, https://www.insideafricalaw.com/publications/mining-royalties-in-focus.

28. Cfr.: Christopher G. Baldwin, Understanding Royalty Structures. Structuring More Effective Mining Ventures, (Conference Board of Canada, February 17-18, 2003). 
ambas partes puesto que la verificación de los cálculos resulta más sencilla y, además, tienen menos riesgo de ser manipuladas por el operador. $^{30}$

\section{Pactos típicos en los contratos de regalía.}

Cada contrato de regalías en el marco de un financiamiento alternativo puede tener sus propias particularidades y disposiciones contractuales dependiendo del tipo de regalía aplicado y las condiciones específicas de la transacción. Sin embargo, en general, los contratos de regalías que se usan para fines de financiamiento contienen los pactos que describiremos a continuación. ${ }^{31}$

\subsection{Condiciones precedentes al desembolso.}

Los contratos de regalía en estructuras de financiamiento alternativo generalmente contienen una serie de condiciones precedentes que tienen que verificarse antes de cada desembolso. Estas condiciones precedentes tienen como finalidad que la empresa de royalties pueda optar por no efectuar el desembolso ante eventos que puedan modificar las condiciones bajo las cuales se firmó el contrato.

Las condiciones precedentes son diferentes a las condiciones suspensivas reguladas en el Código Civil y, por tanto, no se le aplicarán las reglas previstas en él -como por ejemplo, el artículo 172 del Código Civil que señala que es nulo un contrato cuando se pacte una condición meramente potestativa-. ${ }^{32}$

Las condiciones precedentes en este tipo de transacciones están enfocadas en asegurar que las condiciones existentes a la firma del contrato se mantengan a la fecha de desembolso. Así, se establece como condiciones precedentes al desembolso que las declaraciones y garantías del operador continuen siendo veraces, ciertas y completas, que no haya incumplimeinto con relación a las obligaciones que debieron ser cumplidas para ese momento, que no existan investigaciones o procedimientos contra el operador que puedan afectar la regalía, que las concesiones mineras continuan vigentes, entre otras.

En algunos casos se incluye como condición precedente el hecho que no haya ocurrido un "Material Adverse Effect" o "Efecto Sustancialmente Adverso". Esta condición precedente permite a la empresa de royalties no realizar el desembolso si ha ocurrido algún evento que afecte sustancialmente los negocios, operaciones, condición financiera del operador o del proyecto minero y generalmente excluyen cambios el mercado financiero, la economía global, el precio de los metales.

\subsection{Determinación y pago de las regalías.}

Las regalías no serán exigibles hasta que se haya completado el desarrollo del proyecto minero, la

30. Cfr.: Christopher G. Baldwin, Op. Cit., 12.

31. Para una descripción de los pactos típicos generalmente usados en la industria minera canadiense en contratos de regalías, ver: Karl J.C. Harries, «Mining Royalty Agreements Between Private Parties: the Relationship Between Payer and Recepient», Journal of Energy \& Natural Resources Law 14, n³ (1996), 354-381. Asimismo, se puede ver el modelo de contrato de regalías — AMPLA Model Royalty Deed o Modelo AMPLA — preparado por la Australian Mining and Petroleum Law Association - AMPLA—. Cfr. Grace, John y Robert Bassett.

32. Al respecto, concordamos plenamente con lo señalado por Sergio García Long, quien diferencia a las condiciones precedentes - conditions precedent-, que tienen su origen en el derecho anglosajón, de las condiciones suspensivas reguladas en el Código Civil y que generan la ineficacia inmediata y de pleno derecho de un contrato. En primer lugar, señala García Long, las condiciones precedentes no generan la ineficacia del contrato sino que funcionan como un presupuesto para pasar a otra etapa del mismo y, eventualmente, otorgan un derecho potestativo a resolver el contrato. Cfr.: Sergio García Long, «La estructura contractual de los financiamientos bancarios», en Derecho Contractual Financiero. Estudios en Homenaje a la Facultad de Derecho PUCP en su Centenario, coordinado por Sergio García Long, (Lima: Normas Jurídicas Ediciones, 2019). 
operación minera comience su producción comercial y, efectivamente se generen ingresos por la venta de minerales extraidos de la concesión minera. Para tal efecto, el operador del proyecto deberá notificar al titular de la regalía sobre el inicio de la operación comercial con algunos días de anticipación y, luego de recibido el primer pago por la venta de los minerales, el operador deberá calcular y pagar la regalía periódicamente. Una vez que sean exigibles, las regalías tendrán una duración indefinida y deberán ser pagadas mientras se produzcan y vendan minerales de las concesiones mineras a las que se vinculan.

La determinación y cálculo del monto de regalías a ser pagado en cada oportunidad corresponde al operador del proyecto, quien deberá sustentar su cálculo con un reporte escrito. Para efectos de determinar las regalías NSR, que son las más comunes, existen dos definiciones clave: Ingresos brutos - Gross Revenue - y Deducciones Permitidas - Allowable Deductions-. En el Modelo AMPLA —AMPLA Model Royalty Deed preparado por la Australian Mining and Petroleum Law Association-, la definición de Gross Revenue incluye todos los ingresos registrados por ventas de minerales al precio de venta pactado o basado en precios de referencia de mercado e incluye ingresos por seguros, menos deducciones por penalidades, reembolsos, reclamos o descuentos. Asimismo, se excluyen los resultados de actividades de trading tales como ventas forwards, futuros, opciones o el uso de instrumentos de cobertura. Por su parte, la definición de Allowable Deductions bajo el Modelo AMPLA es amplia e incluye los gastos en que se incurriría entre la mina y una refinería, excluyendo gastos de exploración, desarrollo y operación de la mina.

Para estos efectos, generalmente se establece que los ingresos por la venta de los minerales deberán hacerse en condiciones de mercado y bajo términos comerciales ordinarios - arms-length basis-. En caso el titular de la regalía tenga objeciones a la determinación de la regalía y las partes no consigan ponerse de acuerdo entre ellas, se somenterá la disputa a la determinación de un tercero quien auditará los registros contables del operador relativos al cálculo de la regalía.

En algunos casos, particularmente en el caso de regalías sobre metales preciosos, como lo son el oro o la plata, se establece que, a elección del titular de la regalía, las regalías podrán ser pagadas en especie; es decir, a través de la entrega de los metales producidos.

\subsection{Declaraciones y garantías.}

Las declaraciones y garantías son manifestaciones sobre situaciones fácticas o legales relativas al declarante, sus negocios o algún activo de su propiedad cuya finalidad es reducir la asimetría informativa entre el declarante y el receptor de la declaración. Desde el punto de vista económico, debería existir un incentivo común entre las partes para reducir la asimetría informativa y los costos para adquirir información a través de declaraciones y garantías, pues asignan el riesgo a la parte que está en capacidad de asumirlo al menor costo posible. Por ello resultan mutuamente beneficiosas. ${ }^{33}$

Desde el punto de vista legal, las declaraciones y garantías son "una relación jurídica de garantía, por la cual, una parte asume un riesgo a cambio de una contraprestación y se obliga a indemnizar a su contraparte en caso el riesgo materialice". ${ }^{34}$ En algunos casos, como en el caso de adquisición de empresas o activos, el remedio ante su incumplimiento será el pago de un monto dinerario denominado indemnity, que funciona como un ajuste del precio pagado; mientras que en el caso de financiamientos, el

33. Para una explicación sobre la racionalidad económica de las declaraciones y garantías ver: Ronald J. Gilson, «Value Creation by Business Lawyers: Legal Skills and Asset Pricing», 94 YALE L. J. 239 (1984). Disponible en: https:// scholarship.law.columbia.edu/faculty_scholarship/986.

34. Cfr.: Sergio García Long, Op. Cit., 74. 
remedio contractual será la suspensión de los desembolsos o aceleración del préstamo. En consecuencia, en la medida que la falsedad o inexactitud de las declaraciones y garantías tienen consecuencias relevantes bajo el contrato, suelen ser cláusulas bastante negociadas.

En los contratos de regalías, las declaraciones y garantías realizadas por el titular de la concesión minera - deudor-son relativamente amplias y tienen como finalidad que el beneficiario de la regalía entienda la situación del titular del proyecto, así como de las concesiones mineras y el proyecto minero sobre cuya producción se han pactado las regalías.

Los contratos de regalías típicamente incluyen declaraciones y garantías sobre la existencia del titular y operador del proyecto minero, la obtención de aprobaciones corporativas requeridas, la validez y eficacia del contrato de regalías y su no contravención de normas, contratos o documentos societarios, la ausencia de procedimientos de reoganización societaria o insolvencia, la titularidad y vigencia de las concesiones mineras relevantes, la inexistencia de procedimientos 0 litigios que puedan afectar las concesiones mineras o la regalía, el cumplimiento de las leyes aplicables, la obtención de permisos necesarios para el desarrollo del proyecto - en el estado en el que se encuentren-, entre otros. Asimismo, en Perú son particularmente relevantes las declaraciones sobre la inexistencia de mineros ilegales o informales en el área del proyecto, así como de conflictos sociales que pueden impedir el desarrollo del proyecto.

La falsedad de alguna declaración y garantía, dependiendo del momento en el que se produce puede ocasionar que se suspenda el desembolso, resuelva el contrato o, eventualmente, que el titular de la regalía pueda reclamar una indemnización por los daños que se le hayan causado, aunque este último supuesto no es muy usual.

\subsection{Decisiones sobre la operación y el desa- rrollo del proyecto.}

Los contratos de regalía generalmente contienen disposiciones que establecen expresamen- te que el operador tomará las decisiones con relación a la exploración, desarrollo y operación del proyecto minero. La única limitación que se le impone es que estas decisiones deberán ser realizadas de conformidad con las leyes aplicables y las buenas prácticas de la industria minera. Esto tiene mucho sentido, puesto que el titular de la regalía no es un socio en el proyecto.

Al respecto, el Modelo AMPLA establece que: (a) el deudor tendrá derecho a conducir las operaciones de exploración y explotación siempre que lo haga de manera segura y diligente y de una manera comercialmente razonable de acuerdo con las mejores prácticas mineras internacionales; (b) el titular de la regalía no debe interferir con las operaciones del operador del proyecto; (c) el deudor debe mantener las propiedades mineras vigentes, pero no asume niguna obligación de explorar, desarrollar o explotarlas; y (d) el deudor tiene total discreción para decidir en todas las etapas del proyecto minero y no será responsable for minerales que se puedan perder o regalías que se dejen de pagar por sus decisiones.

\subsection{Derecho de recompra.}

Los contratos de regalía generalmente conceden al operador el derecho a "recomprar" toda o parte de la regalía por un precio fijo durante un periodo de tiempo y usualmente antes que comience la operación comercial. El precio de recompra es generalmente mayor al pago inicial efectuado a cambio de la regalía y debería representar la apreciación en el valor de la regalía por el avance del proyecto minero.

El derecho de recompra es claramente beneficioso para el deudor de la regalía, puesto que será éste quien decidirá si ejerce o no el derecho dependiendo de los prospectos del proyecto. Por ello, debería ser cuidadosamente negociado, particularmente por el beneficiario de la regalía. Por ejemplo, el beneficiario de la regalía puede requerir que el derecho de recompra sólo aplique a una porción de la regalía y, de esa manera, negociar un nuevo precio de recompra o retener esa parte de la regalía. El beneficiario también podría exigir que, ante

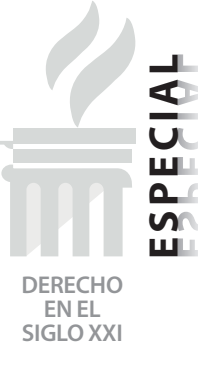


determinados eventos, el deudor esté obligado a ejercer el derecho de recompra.

\subsection{Derecho de preferencia.}

Los contratos de regalía usualmente contienen un derecho de adquisición preferente a favor del operador en caso el titular de la regalía reciba una oferta de compra de un tercero no vinculado que esté dispuesto a aceptar. De la misma manera, algunos contratos de regalía contienen un derecho de adquisición preferente a favor del titular de la regalía en caso el operador tenga la intención de celebrar un nuevo contrato de regalías o streaming con un tercero en relación con el proyecto minero.

En ambos casos se deberá notificar la recepción de la oferta y la contraparte tendrá la facultad de ejercer o no su derecho de adquisición preferente en los mismos términos ofrecidos dentro de un plazo determinado.

\subsection{Entrega de información y derecho de ins- pección.}

Los contratos de regalía incluyen obligaciones de entrega periódica de información sobre la producción minera histórica y proyectada, recursos y reservas, información financiera del operador, así como información que permita al titular de la regalía verficar que el cálculo de la regalía haya sido correctamente efectuado. Asimismo, se otorga al titular de la regalía el derecho de inspeccionar el proyecto minero a su costo y riesgo.

\subsection{Transferencia de las concesiones mineras.}

Los contratos de regalía establecen restricciones a la transferencia de las concesiones mineras vinculadas a la regalía. En efecto, generalmente se pacta que el operador no podrá transferir las concesiones mineras salvo que: (a) el titular de la regalía consienta la transferencia o; (b) que el adquirente, el titular de la regalía y el operador celebren un acuerdo en virtud del cual el adquirente asuma las obligaciones bajo el contrato de regalía.

\section{Garantías.}

Las obligaciones del operador del proyecto, en particular el pago oportuno de la regalía, pueden garantizarse con garantías personales o reales, tales como una hipoteca minera sobre las concesiones mineras para mitigar el riesgo de incumplimiento del deudor. Esto, claro está, siempre presentará algunas complicaciones en la relación con los acreedores financieros potenciales o existentes, quienes siempre exigirán garantías prioritarias y preferntes.

\section{CONSIDERACIONES FINALES}

Como hemos podido apreciar, las regalías se han convertido en un mecanismo alternativo para el financiamiento de proyectos y operaciones mineras que, por sus múltiples beneficios tanto para las empresas mineras como para los inversionistas, viene adquiriendo mayor protagonismo en el mercado.

Sin embargo, como la mayoría de estructuras financieras, tiene su origen en otras jurisdicciones $y$, por lo tanto, las estructuras contractuales utilizadas son generalmente importadas debiendo ser adaptadas a la realidad y legislación peruana. La falta de regulación expresa de las regalías contractuales mineras en Perú, así como su categorización como relación obligacional y falta de persecutoriedad, presentan algunas complicaciones que los operadores jurídicos deberán tener en consideración al diseñar las estructuras contractuales para poder implementar estas transacciones. Esas estructuras deberán, en la medida de lo posible, satisfacer las expectativas de las partes, particularmente las empresas de royalties que en su condición de financiadores asumen los mayores riesgos, y replicar las condiciones usuales del mercado internacional. 